\title{
AVALIAÇÃO DO PROCESSO ENSINO-APRENDIZAGEM: SEU SIGNIFICADO PARA O ALUNO DE ENSINO MÉDIO DE ENFERMAGEM*
}

\author{
ASSESSMENT OF THE TEACHING-LEARNING PROCESS: ITS MEANING FOR \\ STUDENTS HOLDING A HIGH SCHOOL DIPLOMA OR EQUIVALENT AND \\ ATTENDING A NURSING PROGRAM
}

\author{
EVALUACION DEL PROCESO ENSENANZA-APRENDIZAJE: \\ SIGNIFICADO PARA EL ALUMNO DE ENSEÑANZA DEL NIVEL MEDIO \\ DE ENFERMERÍA
}

Marcos Antonio da Eira Frias** Regina Toshie Takahashi***

Frias MAE, Takahashi RT. Avaliação do processo ensino-aprendizagem: seu significado para o aluno de ensino médio de enfermagem. Rev Esc Enferm USP 2002; 36(2): 156-63.

\section{RESUMO}

Este estudo, realizado com alunos de uma escola particular de enfermagem da cidade de São Paulo, objetivou compreender o significado da avaliação para o educando de nível médio. Para a coleta de dados utilizamos um instrumento contendo a pergunta: "qual o significado da avaliação para você enquanto aluno de um curso de auxiliar de enfermagem"? Os discursos foram analisados, segundo o referencial de BARDIN, na modalidade análise de conteúdo. Os resultados mostram a avaliação pautada num conjunto de significados que convergem para as categorias ENSINO-APRENDIZAGEM, FATORES EMOCIONAIS e PAPEL DO PROFESSOR.

PALAVRAS-CRAVE: Avaliação do ensino. Educação em enfermagem. Auxiliares de enfermagem. Técnicos de enfermagem.

\begin{abstract}
This study aimed at gaining an understanding of what the assessment meant to students holding a high school diploma or equivalent and attending a nursing program. It was carried out at a private nursing school in the city of Seto Paulo, Brazil. Data was gathered through a tool containing the following question: "what does assessment mean to you as a student of a nursing assistant program"? The essays received were classified qualitatively according to the BARDIN frame of reference. Results show that students perceive assessment as a set of meanings that converge toward what we call the TEACHING-LEARNING PROCESS, EMOTIONAL FACTORS and The ROLE OF THE TEACHER.
\end{abstract}

KEYWORDS: Evaluation of the teaching process. Nursing education. Nursing assistants. Practical

nurses.

\section{RESUMEM}

Este estudio, realizado con alumnos de una escuela particular de enfermeria en la ciudad de Sao Paulo, tuvo como objetivo comprender el significado de la evaluación para el educando del nivel medio de enfermería. Para la recolección de los datos utilizamos un instrumento conteniendo la siguiente pregunta: Para usted iCuál es el significado de la evaluación como alumno de un curso de auxiliar de enfermeria?. Los discursos fueron analizados, según el referencial de BARDIN, siguiendo la modalidad de análisis de contenido. Los resultados muestran la evaluación pautada en un conjunto de significados que convergen para las categorias ENSENANZAAPRENDIZAJE, FACTORES EMOCIONALES y PAPEL DEL PROFESOR.

PALABRAS-CLAVE: Evaluación dela enseñanza. Educación en enfermeria. Auxiliares de enfermería. Técnicos de enfermeria.

Texto extraído da Dissertação de Mestrado apresentada a E.E.U.S.P.- Defesa em 18 de setembro de 2001. Apresentado no 53 CBEnf - Curitiba no dia 13 de outubro de 2001 na sessão tema livre sob o título: Avaliação do processo ensino-aprendizagem: qual seu significado para o aluno de ensino médio de enfermagem?

** Enfermeiro, Mestre em Enfermagem pela Escola de Enfermagem da Universidade de São Paulo, Prof responsável pela Disciplina Enfermagem Geriátrica e Prof. assistente da Disciplina Semiologia e Semiotécnica de Enfermagem da Faculdade de Enfermagem do Hospital Israelita Albert Einstein. E-mail: marcos.eirafrias@ig.com.br***

*** Enfermeira, Professora Doutora do Departamento de Orientação Profissional da Escola de Enfermagem da Universidade de São Paulo, Orientadora. 


\section{INTRODUÇÃO}

A palavra avaliar é originária do latim e provém da composição a-valere, que significa "dar valor a...". No entanto, o conceito "avaliação" é expresso como sendo a "atribuição de um valor ou qualidade a alguma coisa, ato ou curso de ação...", implicando "um posicionamento positivo ou negativo em relação ao objeto, ato ou curso de ação avaliado" (1).

Alguns autores, como Libâneo(2), Luckesi(3), definem a avaliação corno:

"(...) um componente do processo de
ensino que visa, através da verificação e
qualificação dos resultados obtidos,
determinar a correspondência destes com
os objetivos propostos e, daí, orientar a
tomada de decisões em relação às
atividades didáticas seguintes" (2).

"(...) um juizo de qualidade sobre dados relevantes, tendo em vista uma tomada de decisão" (3).

O processo avaliativo apresenta algumas características que o diferem da medida, embora contenha a medida como condição necessária à sua objetividade e precisão ${ }^{(4-5)}$

A avaliação da aprendizagem como processo deve buscar a inclusão e não a exclusão dos educandos. Portanto, o professor ao avaliar o aluno, deve levantar dados, analisá-los e sintetizá-los, de forma objetiva, possibilitando o diagnóstico dos fatores que interferem no resultado da aprendizagem $(2 ; 6-8)$

O objeto de análise da avaliação do rendimento escolar é a expressão global do aluno, ou seja, sua expressão de forma oral, escrita, corporal ou gestual, tanto na área cognitiva, afetiva-social quanto na psicomotora (7).

"A avaliação deverá ser assumida como um instrumento de compreensão do estágio de aprendizagem em que se encontra o aluno, tendo em vista tomar decisões suficientes e satisfatórias para que possa avançar no seu processo de aprendizagem" (3).

Compete à avaliação a verificação e a qualificação. A verificação acontece por meio das informações levantadas pelo professor nas provas, exercícios, tarefas e observação do desempenho dos alunos. A qualificação acontece por intermédio da comprovação dos resultados alcançados, tendo em vista os objetivos e, conforme o caso, atribuição de notas ou conceitos ${ }^{(2)}$

Podem ser atribuídas à avaliação educacional funções gerais e específicas. As funções gerais fornecem o embasamento para o planejamento e possibilita a seleção e a classificação de pessoas e o ajustamento da política educacional e das práticas curriculares. As funções específicas permitem o diagnóstico, o controle e a classificação(9).

O diagnóstico possibilita identificar, discriminar, compreender e caracterizar os fatores desencadeantes das dificuldades de aprendizagem (2,5,7,9).

O controle visa localizar, apontar, discriminar deficiências e insuficiências no desenvolvimento do processo ensino-aprendizagem e corrigi-las por meio de um controle sistemático e contínuo, que se dá pela interação professor-aluno, durante as aulas (2,9-10)

A "função de classificação propicia principalmente a efetivação do propósito de classificar o aluno, segundo o nivel de aproveitamento, ou rendimento alcançado, em comparação ao grupo de classe" (9).

\section{OBJETIVO}

Este estudo teve como objetivo compreender o significado da avaliação escolar para os alunos de ensino médio de enfermagem de uma escola particular na cidade de São Paulo.

\section{TRAJETÓRIA METODOLÓGICA}

A metodologia utilizada foi a qualitativa, na vertente da Análise de Conteúdo. A análise de conteúdo é definida por Bardin(11) como sendo um conjunto de instrumentos metodológicos, os quais se aplicam aos "discursos" mais diversos e tem como meta a indução, a dedução e a conclusão.

O estudo foi realizado em uma escola particular de enfermagem de Nível Médio, situada na região central da Cidade de São Paulo, sendo sua mantenedora uma instituição de ensino e pesquisa na área de oncologia.

A escolha do local foi motivada por termos ali vivenciado o processo de estruturação, quando atuamos como docente e diretor.

Os participantes deste estudo foram os alunos que cursavam a Qualificação Profissional de Auxiliar de Enfermagem, na escola eleita, no mês de novembro de 2000. Adotou-se como critério de inclusão os alunos avaliados em disciplina teórica e estágio curricular e presentes no dia da coleta de dados.

No período da coleta de dados, a escola contava com uma única turma composta de 17 (dezessete) alunos. Desse total, 01 (um) foi excluído por não estar presente no dia da coleta, 02 (dois) por não terem respondido a pergunta, restando assim, 14 (catorze) participantes com seus respectivos discursos. 
A coleta de dados foi realizada após autorização, por escrito, da Comissão de Ética e Pesquisa da Instituição e do consentimento livre e esclarecido dos participantes. Utilizou-se um instrumento testado previamente com a pergunta: "qual o significado da avaliação para você, enquanto aluno de um curso de auxiliar de enfermagem?".

Para a análise dos dados, transcrevemos o discurso dos participantes ipsis litteris, permitindo assim uma leitura mais fluente, sem os obstáculos da grafia de cada um dos manuscritos.

Após a transcrição literal dos dados, passamos, então, ao primeiro momento descrito como pré-análise (periodo das intuições).

No segundo momento, definido como exploração do material, fizemos a "análise propriamente dita (...) que consiste essencialmente de operações de codificação (... )" ( 11)

Para alcançar o significado, utilizou-se um quadro (Anexo), em que os vários significados da avaliação foram categorizados pelo critério semântico (categorias temáticas).

Este primeiro agrupamento deu origem a várias categorias, das quais algumas apresentavam relação entre si e, a partir de um segundo agrupamento, pôdese, então, definir três categorias: CATEGORIA 1: ENSINO-APRENDIZAGEM composta de três subcategorias a saber, "expressão global"; "perceber o aprendizado" e "aprender constante"; CATEGORIA 2: FATORES EMOCIONAIS; CATEGORIA 3: PAPEL DO PROFESSOR.

No terceiro momento, definido como tratamento dos resultados obtidos e interpretação, buscou-se determinar os conceitos significativos e válidos, em que os dados foram tratados, a partir da inferência e interpretação.

\section{ÃPRESENTAÇÃO E ÃNÁLISE DOS RESULTÃDOS*}

\section{Categoria Um: "ENSINO-APRENDIZAGEM"}

Após o agrupamento das falas, pudemos observar que algumas delas convergiam para o mesmo ponto, o processo ensino-aprendizagem, surgindo, então, a primeira categoria, a qual denominamos "ENSINO-APRENDIZAGEM".

$\mathbf{O}$ ensino-aprendizagem não acontece em um espaço restrito da sala de aula, pode acontecer "(...) em todos os ambientes e situações (...), só as pessoas que não têm uma atitude de constante abertura é que não aprendem ou não ensinam em todas as situações (...) a avaliação se desenvolve nos diferentes momentos do processo ensino-aprendizagem" (12).

\section{Subcategoria um: "expressão global"}

A primeira subcategoria, denominada expressão global, pode ser observada nas falas de alguns dos participantes deste estudo, demonstrando sua visão em relação à avaliação.

A expressão global do aluno é o objeto de avaliação que, das mais variadas formas, deixa

transparecer os progressos e as dificuldades do educando e que, no nosso entender, estão representadas nesta subcategoria.

Nos discursos, percebe-se que os alunos ressaltam a importância da atenção do professor ao observar e avaliar continuamente todas as atitudes que demonstrem aprendizado.

Campoy et al. (13) referem que os professores participantes de seu estudo demonstram, por meio dos discursos, compreender as várias interações exigidas durante o processo avaliativo. No entanto, não conseguem perceber como podem atuar diante de tantas dificuldades, embora alguns tentem encontrar formas para minimizá-las.

A formação de profissionais de nivel técnico deve proporcionar ao aluno o desenvolvimento gradual das habilidades, um comportamento considerado ético, mostrar o quanto aprendeu e o quanto conseguiu desenvolver, em termos de capacidade e agilidade de raciocínio, e desenvolver a habilidade no manejo de materiais e equipamentos. No nosso entender, este é o objeto de observação e de avaliação na formação dos profissionais de enfermagem.

A utilização do termo avaliar se refere não apenas aos aspectos quantitativos, mas também aos qualitativos da aprendizagem, os quais abrangem a aquisição de conhecimentos e informações, resultantes dos conteúdos curriculares estabelecidos, como também das habilidades, interesses, atitudes, hábitos de estudo e ajustamento pessoal e social (5).

Alguns desses aspectos qualitativos, citados por Haydt (5), estão presentes nos seguintes relatos:

\footnotetext{
"Avaliar a responsabilidade, o interesse, a compreensão, a habilidade a maturidade do aluno é muito importante para o educador (...)"

" (...) analisar, em todos os aspectos, que estou apta para ingressar ou não na profissão."
}

\footnotetext{
Para efeito de publicação, apresentamos apenas algumas falas dos sujeitos.
} 
Verificamos, nos discursos, a importância dada pelo aluno para a necessidade de ser responsável, ter interesse, compreensão, maturidade e estar capacitado para exercer a profissão, o que, no nosso entender, demonstra preocupação com sua formação.

"A sociedade atual exige pessoas competentes, com vários talentos, desenvolvidos e avaliados na escola, no interjogo de interesses e atividades individuais e coletivas" (14).

Entendemos que esta nova exigência da sociedade se dá em virtude de toda a evolução dos últimos anos, por meio dos grandes investimentos em tecnologia, exigindo dos profissionais, já inseridos no mercado de trabalho, a requalificação em serviço e dos novos ou futuros profissionais que se apresentem com conhecimento técnico e científico que os habilite a ingressar nesse mercado de trabalho de novas tecnologias.

Do nosso ponto de vista, essas novas exigências interferem diretamente na formação dos profissionais de nível técnico de enfermagem, levando professores, alunos e a escola, de um modo geral, a enfrentarem conflitos, pois, na maioria das instituições, a avaliação ainda se presta única e exclusivamente à atribuição de notas, desconsiderando o fato de que ser competente é um conceito muito mais amplo e vai além do dominio de conteúdos. Implica domínio de habilidades intelectuais, que possibilitam experiências mínimas necessárias na busca contínua de novos conhecimentos; desenvolvimento de habilidade nas relações humanas, que permitam ao profissional exercer as atividades embasadas em preceitos éticos e morais, aceitos pela sociedade em que está inserido, e habilidades manuais que desenvolvam a destreza na utilização de materiais e equipamentos, cada vez mais sofisticados incorporados na assistência de enfermagem, assistência essa que, até bem pouco tempo, era quase puramente artesanal. A visão sobre a avaliação dos conhecimentos teóricos e da prática, em estágio, deve estar voltada para o quanto o aluno detém de saber e sua capacidade de relacionar esse saber com a prática, revertendo numa assistência segura e eficiente.

\section{Subcategoria dois: "perceber o aprendizado"}

A subcategoria dois, "perceber o aprendizado", presente nos discursos dos alunos, demonstra a função da avaliação no processo ensinoaprendizagem.

A avaliação conduz o aluno a perceber o seu aprendizado, sem a qual torna-se impossivel a tentativa de sanar suas dificuldades, permitindo, assim, a retomada e a recondução da aprendizagem. De nada adianta somente o professor perceber as dificuldades ou o que o aluno aprendeu. $\mathrm{O}$ aluno como sujeito do processo de avaliação, deve ter consciência e reconhecer suas dificuldades, erros e acertos e trocar informações com o professor, para que, em conjunto, consigam então retornar ao aprendizado.

Segundo Haydt(5), "(...) a avaliação pode ser útil para orientar tanto o aluno como o professor: fornece informações ao aluno para melhorar sua atuação e dá elementos ao professor para aperfeiçoar seus procedimentos didáticos".

Corroborando essa visão, Frias et al.(15) referem que a avaliação deve ser um processo continuo e progressivo que subsidie o replanejamento por meio de uma análise da situação vivenciada.

"Independente da modalidade de avaliação que se possa estar desenvolvendo, transparece a figura do professor mediador, próximo, atento, perguntando, acompanhando, substituindo-se o conceito de avaliação como controle pelo de avaliação como diálogo reflexivo, de ajuda e de compreensão. O conteúdo desse diálogo trata de resultados e de caminhos percorridos, de dificuldades encontradas e de tomada de decisões" (16).

A interação avaliativa ocorre com maior facilidade quando existe a possibilidade de diálogo aberto, troca de informações, crítica e solidariedade ${ }^{(14)}$.

O diálogo citado por Faria (14); Grillo (16) está expresso no discurso abaixo:

" (...) o início do aperfeiçoamento do aluno $e$, principalmente, após esta avaliação, o aluno e o professor devem trocar informação (...)"

Durante muitos anos, nas escolas de ensino técnico de enfermagem, os alunos foram "adestrados" para obedecer as ordens. Seu saber era desconsiderado e o professor estava próximo, atento e acompanhando para confirmar se o aluno conseguia ou não desenvolver as atividades que lhe eram atribuídas.

Hoje, percebe-se uma mudança radical em algumas escolas, onde o professor deixou de estar próximo, para estar junto ao aluno, atento às necessidades de orientação, acompanhando o desenvolvimento de cada discente para reorientar e redirecionar o aprendizado. A ênfase na construção do saber é uma realidade, os alunos são estimulados e levados a desenvolver atividades de estudo em grupo, buscar e comparar informações, em várias bibliografias, participar de cursos e encontros estruturados especificamente para eles, abrindo-se, assim, um leque de possibilidades de novos conhecimentos. Diante dessa realidade, a avaliação necessita tomar novo rumo, para que possa, então, se estabelecer o diálogo aberto, a troca de informações e a solidariedade citadas por Faria (14).

Ainda nesta subcategoria, aparecem, nos relatos abaixo, a expressão do aluno como forma de mostrar 
o seu aprendizado, a possibilidade de perceber $\mathrm{o}$ aprendizado e o empenho necessário para o seu aprimoramento.

"(...) demonstrar o que sabe, anotando inclusive dados novos e experiências passadas (...)"

"(...) posso perceber pontos em que eu precise me empenhar mais e com isso melhorar meus conhecimentos (...)"

Por ser dinâmica, a avaliação deve permitir e levar educador e educando à consciência do que foi produzido, em termos de conhecimentos, não podendo, assim, se prender a modelos estáticos que dificultem ou impeçam o aluno e o professor de perceberem os resultados e os sinais indicativos da aprendizagem. Os participantes deste estudo demonstram ter consciência dessa dinamicidade da avaliação que a configura como um meio e não como um fim. A avaliação é um meio que leva o aluno a perceber seus acertos e erros, auto-avaliar e, então, dar continuidade à construção do seu saber e não um fim que o classifica para atestar que está apto para continuar o processo de aprendizado ou que deve ser excluído.

Enricone(19) afirma que "não se coloca dúvida sobre a necessidade do conhecimento teórico e prático oferecido pela escola, mas quando os alunos acumulam, ao longo do sistema educativo, propostas de reprodução do conhecimento, onde o armazenamento das informações tem lugar privilegiado, há o desvirtuamento de uma das características básicas do ensino: fomentar a reflexão e o pensamento crítico".

Podemos observar, nos relatos, a visão de avaliação como reprodução, em que o aluno decora conteúdos e os transcreve quando solicitado.

\section{" (...) uma mera revisão decorativa, posta num papel."}

" A avaliação escrita, muitas vezes não pode avaliar o aluno, pois o mesmo pode não ter entendido a matéria e apenas ter decorado o conteúdo para a avaliação na sua véspera. "

Nos relatos que compõem esta subcategoria, a avaliação se mostra como sendo a possibilidade de adquirir conhecimentos, o aluno iniciar o seu aperfeiçoamento, perceber e mostrar seu aprendizado, provar para si mesmo o quanto de saber foi adquirido, trocar informações com o professor.

Nesta subcategoria, a relação da avaliação com o ensino-aprendizagem está bastante visivel, o que nos leva a afirmar que estes sujeitos têm uma experiência positiva em relação à educação escolar que faz com

que a avaliação se apresente como aprendizado constante, o qual está expresso nas falas agrupadas na subcategoria três.

\section{Subcategoria três: "aprender constante"}

Acreditamos que o professor, enquanto educador comprometido com o aprendizado de seus educandos, deve lançar mão de todos os artificios para motivá-los, artificios estes que podem ser traduzidos como elogios, palavras de incentivo, "sorriso de aprovação", e o próprio resultado da avaliação que deve ser lido com olhos de quem consegue perceber o empenho do aluno e ainda, a partir desses resultados, definir os caminhos a serem seguidos, conduzindo o discente ao aprendizado constante.

"As repercussões apontadas pelos alunos sobre a avaliação são extremamente desejáveis, pois a motivação para estudar e o estímulo para avançar no conhecimento, levam-no a descobrir que aprender não é decorar, que o importante é estudar e produzir conhecimento e não a obtenção da nota; ele constata que, pela mediação dessas experiências positivas de avaliação, ocorreu a aprendizagem e que ele aprendeu porque não copiou modelos, dialogou com o conhecimento, interagiu com o professor" (20).

Resultados semelhantes aos apresentados por Camargo(20) aparecem, nesta terceira subcategoria em que os alunos apontam como sendo significado da avaliação o aprendizado constante que os leva a questionar enquanto pairarem dúvidas, despertar a vontade de aprender coisas novas, melhorando os conhecimentos e que, na maioria das vezes, decorar os conteúdos é desnecessário. Esses resultados podem ser percebidos nos seguintes discursos:

\begin{abstract}
"Aprender sempre, questionar enquanto há dúvidas, decorar, quase sempre desnecessário "

"Fazendo com que o individuo evolua com suas idéias, aperfeiçoe cada dia mais seu conhecimento, tenha vontade sempre de aprender coisas novas. "
\end{abstract}

\section{Categoria dois: "FATORES EMOCIONAIS"}

Esta categoria se configura pelo discurso de alguns dos participantes do estudo e se caracteriza pelo fato de a avaliação despertar sentimentos que dificultam ou impedem que eles se expressem, consigam mostrar seu conhecimento e o quanto foram capazes de assimilar, traduzindo-se na "leitura do professor" como se o aluno não fora detentor de tais conhecimentos.

Um dos equívocos cometidos por alguns professores, na avaliação, é o fato de considerar que as provas são prejudiciais ao desenvolvimento da autonomia das potencialidades e da criatividade dos educandos, pois acreditam que, sendo a aprendizagem 
resultante da motivação interna do aluno, toda situação de prova leva à ansiedade, à inibição e ao cerceamento do crescimento pessoal. Por isso, recusam qualquer quantificação dos resultados (2).

Não somos contrários à avaliação que visa direcionar o desenvolvimento do processo ensinoaprendizagem e, conseqüentemente, o desenvolvimento do discente, somos contrários sim à avaliação que tem o objetivo único de classificar (ou desclassificar) o educando, pois, como Luckesi (21), acreditamos que a avaliação da aprendizagem deva ser um suporte que possibilita qualificar o que está acontecendo com o aluno, agir no sentido de ajudá-lo a alcançar o que se pretende, sendo, portanto, uma "fonte de decisão sobre os caminhos do crescimento sadio e feliz".

A avaliação, na fala desses sujeitos, desencadeia reações que os impedem parcial ou totalmente, de se expressar. Essas reações, no nosso entender, podem ocorrer tendo em vista que, ainda hoje, nas escolas, a "nota da prova" é que vai confirmar ou negar a possibilidade de acesso a outros níveis de formação. A percepção dos discentes sobre avaliação se apresenta ligada a fatores emocionais que são reflexos da dificuldade de expressão escrita e falta de consciência sobre a importância de seu saber para a futura vida profissional. A preocupação com a nota faz com que eles apenas decorem os conteúdos mínimos necessários para garantir aprovação. discursos:

Esses dados podem ser observados nos seguintes

" Eu não me incomodo, mas me preocupo com uma nota vermelha."

" (...) muitas vezes, só em saber que você irá ser avaliado, o nervosismo toma conta $e$, no apavoramento, acaba dando os famosos 'brancos', muitas vezes, gerando dificuldade de 'expressão escrita'."

"A escola deve criar um ambiente estimulante, que valorize a invenção e a descoberta, na qual os alunos possam construir sua aprendizagem, aprendendo a aprender, pesquisando e reconstruindo, sem medo da avaliação realizada pelos mestres e colegas" (14)

Para que se concretize essa afirmação, no âmbito da formação técnica de enfermagem, se faz necessário um comprometimento do educador. No nosso entender, muitas vezes, o potencial e a importância dos técnicos e auxiliares não são considerados pelo enfermeirodocente, durante o período de formação. Esses alunos são considerados tarefeiros e não futuros profissionais habilitados a prestar a assistência (que nos compete por direito como enfermeiro), que a eles delegamos.

Frias \& Takahashi (22); Val et al. (23); Carvalho et al. (24)) Antunes (25); Porfirio et al. (26); Vieira (27), em seus estudos, fazem referência aos discentes dos cursos de nível técnico de enfermagem que têm formação superior, completa ou incompleta, em números que variam entre $0,4 \%$ a $17,7 \%$.

Segundo esses autores, a graduação em enfermagem foi um dos cursos superiores que foram relatados pelos pesquisados como incompleto.

Sendo assim, o enfermeiro-docente deve ser capaz de conduzir cada um de seus alunos à construção do aprendizado, valorizando todo o conhecimento (inclusive o conhecimento prévio), dando ênfase à qualidade dessa formação e não simplesmente quantificando os acertos e erros dos passos de uma técnica de enfermagem.

Consideramos relevante reafirmar que compete ao professor transformar a visão negativa que ainda paira sobre a avaliação. Essa transformação deve primeiro acontecer com o professor, de forma que ele esteja "aberto" às manifestações de aprendizado do aluno, o que consideramos estar expresso na categoria três.

\section{Categoria Três: "PAPEL DO PROFESSOR"}

"O motivo central do interesse do professor é apreender o significado de suas decisões no cotidiano do processo de aprendizagem de cada aluno. Esse processo, em permanente construção, é uma oportunidade histórica que possibilita, a cada passo, oferecer condições para o desenvolvimento máximo das capacidades individuais e coletivas dos alunos e de si mesmo" (18).

A avaliação do processo ensino-aprendizagem só se concretiza com a participação do professor e aluno. Esta terceira categoria nos mostra que, na concepção de alguns dos participantes, a avaliação se apresenta como a capacidade do professor de: apreender o saber do aluno por meio do que ele é capaz de expressar, detectar as dificuldades e auxiliá-lo na transposição das barreiras, por meio de reorientação, permitir ao docente certificar-se de que o aluno está capacitado para o exercício profissional.

Ao observar as atividades dos alunos, o professor busca compreender qual o potencial de cada um e como pode atuar para favorecer o processo, procurando sinais do que o aluno sabe e do que pode vir a saber (14).

É função do professor reconhecer as diferenças existentes entre os alunos, em relação à capacidade de aprendizado, e esse reconhecimento permite ao professor ajudá-los a superar as dificuldades de aprendizagem, pois é sabido que, para alguns, o aprendizado acontece mais rapidamente do que para outros e, ainda, que alguns têm maior capacidade de aplicar o que lhes é ensinado(5).

As funções descritas por Faria( ${ }^{(14)}$ e por Haydt(5) são expressas pelos alunos nos relatos abaixo, demonstrando que esses sujeitos entendem a avaliação 
como um processo ativo e construtivo, em que o discente deve mostrar o seu saber e não simplesmente reproduzir conhecimentos, cabendo ao professor perceber as dificuldades e reorientar o aluno.

(...) o docente pode perceber quais são minhas dificuldades e me ajudar a superálas."

" O docente, ao perceber a minha dificuldade, me orientará mais para que eu não cometa o mesmo erro. "

A oportunidade de "reconhecer o erro, refazer e reconstruir é uma forma de aprender, aceitando a avaliação como processo natural. Isso acontecerá mais facilmente à medida em que o professor orientar o aluno a incorporar a avaliação em seu cotidiano, como um desafio de auto-aprimoramento, levando o educando a voltar-se para o próprio trabalho realizado, valorizá-lo, reconhecer os erros, procurar corrigi-los e superá-los"(14).

Para que o aluno possa aceitar a avaliação como um processo natural e cotidiano, entendemos que o professor deve ter essa consciência e ter essa consciência implica em acreditar na avaliação como possibilidade de crescimento mútuo, a partir das dificuldades emergentes, as quais deverão ser trabalhadas para dar continuidade ao processo de transformação.

\section{CONSIDERÃÇÕES FINAIS}

A avaliação acontece ancorada num tripé formado pelo avaliador-avaliado-objeto a ser avaliado, tendo como base o processo ensino-aprendizagem. Cada um dos elementos do tripé tem uma função determinada, sendo que a ausência de um desses elementos descaracteriza a avaliação.

O avaliador está representado pelo professor que sintetiza e analisa os dados emergentes, pontua as dificuldades e busca novas estratégias que possibilitam a recondução de todo o processo, caso necessário.

O avaliado, representado pelo aluno, deve desempenhar o seu papel de elemento ativo e expressar todo o seu potencial, reconhecer as dificuldades, buscando cada vez mais novos conhecimentos. Esses conhecimentos devem possibilitar ao educando condições de desenvolvimento das habilidades necessárias ao exercício das atividades inerentes à assistência na futura vida profissional.

O objeto a ser avaliado é representado pela expressão global do aluno, expressão esta que deixa transparecer vários momentos vivenciados pelo educando, durante sua formação. A forma com que o

discente expressa o seu saber transparece o potencial de aprendizado, que deve ser direcionado rumo à aquisição de outros conhecimentos.
A base representada pelo processo ensinoaprendizagem, como um todo, traz à luz o desempenho do avaliador e avaliado, permite a ambos a possibilidade de diálogo com vistas a esclarecer dúvidas, avaliar e redirecionar o processo ensinoaprendizagem

Ao avaliar, o professor não deve, pura e simplesmente, classificar o aluno dentro de padrões

predeterminados e dar o veredicto final, sem antes refletir e ter a certeza de que todas as possibilidades foram esgotadas no sentido de conduzir o educando ao aprendizado.

Os significados expressos pelos sujeitos apontam justamente esse tripé, mostrando assim que eles têm

consciência da importância da avaliação como um instrumento que, quando utilizado visando o crescimento e o desenvolvimento, possibilita a percepção do saber do educando, suas necessidades

de reorientação e como está sendo desenvolvido o processo educacional.

Esperamos, com este estudo, ter aberto um canal que possibilite aos docentes engajados e preocupados com a formação de seus alunos amenizar um pouco suas angústias com relação ao processo de avaliação. Consideramos relevante que os docentes que atuam no ensino de nivel técnico de enfermagem invistam em novas pesquisas e compartilhem com seus pares, as experiências acumuladas ao longo de sua trajetória como educadores. Que a docência, na formação de

nível técnico, não seja vista somente como a possibilidade de o enfermeiro aumentar seus rendimentos. $\mathrm{E}$, ainda, que a educação de nivel técnico não seja vista como um "produto de segunda linha".

Atuar como docente, independente do grau (educação infantil, ensino fundamental, médio, técnico ou superior), exige: compromisso com o aluno, com a instituição e com a sociedade; competência técnica e científica que permita desenvolver as atividades, dentro de um rigor didático-pedagógico e científico; dedicação no desenvolvimento da atividade a que se propõe; e visão de futuro para formar cidadãosprofissionais com condições de concorrer no mercado de trabalho. Não é nossa intenção fazer apologia ao trabalho do educador, pois este não é o objetivo deste estudo. Queremos sim, reafirmar que a preocupação e a ocupação do docente com a avaliação são fatores fundamentais para o desenvolvimento do educando.

\section{REFERENCIAS BIBLIOGRÁFICÃS}

(1) Luckesi CC. Avaliação da aprendizagem escolar. 10' ed. São Paulo: Cortez; 2000. Verificação ou avaliação: o que pratica a escola? p. $85-101$. 
(2) Libâneo JC. Didática. São Paulo: Cortez; 1994. A avaliação escolar; p. 195-220.

(3) Luckesi CC. Avaliação da aprendizagem escolar- $10^{a}$ ed- São Paulo: Cortez; 2000. Avaliação do aluno: a favor ou contra a democratização do ensino? p. 60-84.

(4) Silva CS. Medidas e avaliação em educação. Petrópolis: Vozes; 1991.

(5) Haydt RC. Avaliação do processo ensino-aprendizagem. 6 ed. São Paulo: Ática; 1997. Auto-avaliação; p. 147-56.

(6) Luckesi CC. Verificação ou avaliação: o que pratica a escola? Ideas 1990; 8: 71-80.

(7) Sousa CP. Estudo sobre o significado da avaliação do rendimento escolar. [tese] São Paulo (SP): Faculdade de Educação da PUC; 1990.

(8) Bartolomei SRT. Reflexões sobre avaliação em enfermagem: uma prática eticamente comprometida? [dissertação] Campinas (SP): Faculdade de Educação da PUC; 1998.

(9) Turra CMG, Enricone D, Sant'Anna FM, André LC. Planejamento de ensino e avaliação. Porto Alegre: Sagra; 1993. A avaliação do ensino-aprendizagem; p. 175-230.

(10) Depresbiteris L. O desafio da avaliação da aprendizagem: dos fundamentos a uma proposta inovadora. São Paulo: EPU; 1989.

(11) Bardin L. Análise de conteúdo. Lisboa: Edições 70; 1977.

(12) Piletti C. Didática geral. 23" ed. São Paulo: Ática; 2000. Avaliação; p. 189-231.

(13) Campoy MA, Frias MAE, Iglesias RB, Takahashi RT. O significado do processo de avaliação de alunos de graduação para professores de enfermagem de uma universidade privada da cidade de São Paulo. Rev Cogitare Enferm. No prelo 1999.

(14) Faria ET. Avaliação e interação pedagógica: uma reflexão. In: Enricone D, Grillo M. Avaliação: uma discussão em aberto. Porto Alegre: EDIPUCRS; 2000. p. 69-88.

(15) Frias MAE, Kobayashi EM, Crespo AS, Okane ESH, Leite MMJ. Dificuldades nas técnicas básicas de enfermagem pelos alunos de um curso técnico de enfermagem. Rev Paul Enferm. No prelo 2001.
(16) Grillo M. Construção da avaliação: estratégias metacognitivas. In: Enricone D, Grillo M. Avaliação: uma discussão em aberto. Porto Alegre: EDIPUCRS; 2000. p. 59-68.

(17) Grillo M. Projeto político-pedagógico e prática avaliativa: uma relação necessária. In: Enricone D, Grillo M. Avaliação: uma discussão em aberto. Porto Alegre: EDIPUCRS; 2000. p. 13-26.

(18) Turra CMG. Avaliação e reconstrução contínua da realidade. In: Enricone D, Grillo M. Avaliação: uma discussão em aberto. Porto Alegre: EDIPUCRS; 2000. p. 43-58.

(19) Enricone D. Pressupostos teóricos sobre a prática avaliativaIn: Enricone D, Grillo M- Avaliação: uma discussão em aberto. Porto Alegre: EDIPUCRS; 2000. p. 27-42-

(20) Camargo ALC. O discurso sobre a avaliação escolar do ponto de vista do aluno. Rev Fac Educ 1997; 23 (1/2): 283-302.

(21) Luckesi CC. Avaliação da aprendizagem escolar. $10^{8}$ ed. São Paulo: Cortez; 2000e. Prática escolar: do erro como fonte de castigo ao erro como fonte de virtude; p. 48-59:

(22) Frias MAE, Takahashi RT. O perfil dos candidatos ao curso técnico de enfermagem de uma escola particular da cidade de São Paulo. Rev Esc Enferm USP 2000; 34 (2): 309-16.

(23) Val LF. Caracterização do perfil dos alunos de nível médio auxiliares de enfermagem. Nursing 1999; 2 (9): 17-21. (edição brasileira)

(24) Carvalho DV, Ferreira AA, Matos SS, Antunes MJM. Força de trabalho de enfermagem de nível elementar no Municipio de Belo Horizonte. Rev Bras Enferm 1996; 49 (3): 343-62.

(25) Antunes MJM. O exame de suplência para qualificação profissional de auxiliares de enfermagem em Minas Gerais. Rev Bras Enferm 1995; 48 (3): 304-13.

(26) Porfírio RM, Manzolli J, Gross HB, Santos JRA. Perfil sócioeconômico-cultural do estudante de auxiliares de enfermagem de São Paulo-SP. Rev Bras Enferm 1992; 45 (4): 290-301.

(27) Vieira ALS. Perfil do nível elementar de enfermagem no Estado do Rio de Janeiro: caracterização da demanda para a profissão. Rev Bras Enferm 1992; 45 (1): 15-20.

$\begin{array}{lllllllll}\tilde{\mathbf{A}} & \mathbf{N} & \mathbf{E} & \mathbf{X} & \mathbf{O}\end{array}$

CATEGORIA 1: ENSINO-APRENDIZAGEM

\begin{tabular}{|l|l|l|l|l|l|}
\hline Referência & Discurso dos alunos & Frase indice & Sub categoria & Categoria \\
\hline & & & & \\
\hline & & & & & \\
\hline & & & & & \\
\hline & & & & & \\
\hline
\end{tabular}

Artigo recebido em 09/11/01

Artigo aprovado em 09/09/02 